\title{
At the Expense of Quality
}

\author{
Brittany M. Bond, Tatiana Labuzova, Roberto M. Fernandez \\ Massachusetts Institute of Technology
}

\begin{abstract}
Many organizations use employee referral programs to incentivize employees to refer potential applicants from their social networks. Employers frequently offer a monetary bonus to employees who refer an applicant, and this is often contingent on whether the person is then hired and retained for a given length of time. In deciding whether to refer someone, referrers face a potential role conflict, as they need to balance their motivations for helping connections find job opportunities with concerns regarding their reputations with their employers. To the extent that monetary incentives shift an employee's considerations away from finding the best matches for the employer, referral bonuses may increase the chances that lower-quality candidates are referred. Using a survey vignette experiment, we find that even a small referral bonus increases the likelihood that referrers will refer lower-quality candidates, and they are more likely to refer people they do not know well. We further discuss theoretical and practical implications regarding the efficiency of incentivized referral programs in producing quality applicant pools for employers.
\end{abstract}

Keywords: hiring; employer referral programs; labor market; social networks

Citation: Bond, Brittany M., Tatiana Labuzova, and Roberto $\mathrm{M}$. Fernandez. 2018. "At the Expense of Quality." Sociological Science 5: 380-401.

Received: March 27, 2018

Accepted: April 17, 2018

Published: June 28, 2018

Editor(s): Jesper Sørensen, Mario Small

DOI: $10.15195 / \mathrm{v} 5 . \mathrm{a} 17$

Copyright: (C) 2018 The Author(s). This open-access article has been published under a Creative Commons Attribution License, which allows unrestricted use, distribution and reproduction, in any form, as long as the original author and source have been credited. (0)(1)

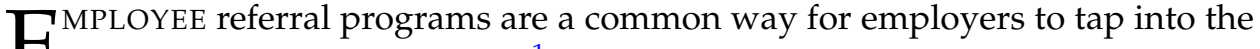
E potential labor market value ${ }^{1}$ within the social networks of current workers (Rubineau 2015; WorldatWork 2016). Employers frequently offer a monetary bonus to employees who refer an applicant who is then hired and retained for a given period of time as a means of incentivizing employees to refer potential applicants (Fernandez, Castilla, and Moore 2000). In conjunction with additional recruitment methods, referral programs are seen as a cost-effective means to access qualified candidates. Substantial evidence demonstrates that employers prefer to hire referred candidates over nonreferred ones (Fernandez and Abraham 2010, 2011; Fernandez and Campero 2017; Fernandez et al. 2000; Fernandez and Greenberg 2013; Fernandez and Mors 2008; Fernandez and Sosa 2005; Fernandez and Weinberg 1997; Petersen, Saporta, and Seidel 2000; for an exception, see Fernandez and Fernandez-Mateo 2006). There is even research supporting a causal interpretation that for otherwise equivalent candidates, employers prefer to hire a candidate who is referred by a current employee over one who is not (Başbuğ 2017; Fernandez and Galperin 2014).

The ubiquity of the use of employee referrals, however, introduces important concerns about the nature of the employment relationship and how people relate to one another outside of the workplace. The notion of an extended internal labor market (EILM [Manwaring 1984]) suggests that employee referrals enjoy many of the labor market benefits that organizational members have by virtue of their participation in a relatively closed labor market (see, e.g., Fernandez and Weinberg 1997). However, it is important to recognize that employees in such systems are likely to experience role conflict (Katz and Kahn 1978). To the extent that people 
are asked to work as recruitment agents on behalf of the firm, referring employees are likely to feel that their obligations to the firm might possibly be at odds with their loyalties to their potential contacts whom they might refer (Heimer 1992). On the one hand, employees might care about their relationships with contacts in their social networks. On the other hand, they may consider the potential damage to their relationship with the employer (Saloner 1985). The decision to refer weighs in the balance of these two motivations.

To the degree that networks facilitate transfers of labor market information, they can improve the matching process between employers and job candidates (Burt 1992; Castilla 2005; Granovetter 1974, 1983; Obukhova 2012). Thus, from the employer's perspective, referral programs appear to have several benefits, including cost savings from generating a "richer pool" of qualified applicants (thereby lowering screening costs) and "social enrichment" processes, which reduce costly turnover for referrals relative to nonreferrals (Fernandez et al. 2000). For networking to help job seekers, however, potential referrers must be willing to provide connections to job seekers (Kim and Fernandez 2017). In this sense, employee referrers act as gatekeepers (Gould and Fernandez 1989) between the employer and a potential candidate they know either socially or professionally outside the focal organization (Bidwell and Fernandez-Mateo 2008; Rubineau and Fernandez 2015).

A number of studies have attempted to study the referring process (e.g., Fernandez and Castilla 2001; Fernandez and Fernandez-Mateo 2006; Fernandez and Sosa 2005;), but all of these studies provide limited insight into referrers' motivation because they only observe those referrals that were actually made. At the same time, ethnographic studies have provided crucial insights about the role conflicts that potential referrers face. In her extensive ethnographic work, Smith $(2003,2005$, 2007,2008 ) documents the phenomenon of reluctant referring in which low-wage employees who feel vulnerable in their jobs and are worried about their reputations with employers are very careful before making referrals to their employer. Based on her field evidence, Marin (2012) argues that potential referrers may also fear that the contact might misconstrue the offer of help as a judgement of the person's current situation, and as a result, potential referrers may decide not to risk sharing the information at all to avoid creating awkwardness or embarrassment.

Under the assumption that an employer desires employee referrals according to either richer pool or social enrichment logics, it is in the employer's interest to encourage referrers to activate their ties rather than operate exclusively toward protecting their reputations or avoiding social awkwardness. To tip the balance of the referral decision in their favor, an obvious way in which employers can motivate their employees to make referrals is to incentivize them by promising bonuses if their referrals make it past certain hiring thresholds. In other words, with the promise of a monetary bonus, the employer can inject an additional strong and salient motivation into the employee referral's consideration of whether or not to activate social ties and refer a social contact to an employment opportunity with the employer.

However, because bonuses may be necessary only for employees who would not otherwise refer someone, such incentives may be counterproductive from the employer's perspective. As a recruiter hiring customer service representative put it, 
"I know people who would refer their dog if they can get a $\$ 250$ bonus" (Fernandez et al. 2000:1333). Thus, it is reasonable to believe that incentivizing the referring of just anyone-especially those who are unlikely to be well suited for the position for which they are being referred-will likely introduce additional burdens on screeners. By adding more low-quality candidates to the hiring system, referral bonus incentives may add costs to the hiring process that are above and beyond any direct cost of the referral bonus reimbursement. Also, adding less-qualified candidates to the candidate pool can increase the likelihood that an underqualified person is hired for an open position, also raising downstream costs to the employer in terms of underperformance. Whether or not referral bonus programs indeed add these potential costs to employers' hiring system depends on whether the promise of a potential referral bonus effectively outweighs the competing loyalty considerations discussed above with regard to referring toward one's employer or toward one's social contacts. To the extent that such considerations prevent less-qualified candidates from entering the applicant pool, such overshadowing may result in unintended negative consequences in the recruitment process.

In this respect, the problem faced by employers here is an example of the general problem of unintended consequences of price incentives: such incentives may encourage behaviors that are counterproductive to the intended goals (Titmuss 1970). One specific concern is that extrinsic rewards might "crowd-out" intrinsic motivation to "do the right thing," vis-à-vis the designers of the policy (Benabou and Tirole 2003; Deci, Koestner, and Ryan 1999; Frey 1994; Frey and Oberholzer-Gee 1997; Gneezy and Rustichini 2000). Whereas the field evidence cited suggests that such counterproductive, unintended consequences might also be encouraged in the context of employee referral programs, the dilemma that potential referrers face (trading off concerns of their employers and their referrals) adds another dimension along which intrinsic motivation might be crowded out (Heimer 1992).

In this article, we seek insight into the mental calculus that referrers use when referring by means of a survey vignette experiment in which we ask subjects to respond to randomly assigned, hypothetical situations in which they might refer someone (for a discussion of the external validity of survey vignettes, see Hainmueller, Hangartner, and Yamamoto 2015). We study the balance of factors affecting a potential referrer's decision to refer or not to refer and how these factors may be affected by the additional consideration of a potential monetary referral bonus. One of the most important factors influencing the decision to refer a given social contact for a job with one's employer is how well the referrer knows the potential referral candidate. The better known the candidate is to the potential referrer, the less tension there is likely to be for an employee deciding whether or not to refer. In general, employees may be more likely to help a candidate they know better. It is likely easier to assess whether the referral will reflect poorly on the referrer's reputation when the potential candidate is better known to the referrer. Likewise, whether or not the referral would appreciate being tapped for the opportunity is likely to be clearer for better known candidates.

To the extent that candidate qualifications and overall fit are more readily known to strong social ties, the tendency for referrers to refer candidates they know well is therefore also likely to be an important consideration in assessing the decision to 
refer. In addition, there might also be nonmonetary motivations associated with the closeness of a tie affecting the decision to refer. Employees may simply have a stronger latent desire to help strong ties connect to job opportunities. Specifically, the desire to help a strong social tie (a "friend") versus a weak one (a "stranger") ${ }^{2}$ find a good job opportunity may also work to motivate people to refer, independent of other considerations (Kim and Fernandez 2017; Bond and Fernandez 2018). For this reason, too, potential referrers should be more likely to make referrals when considering candidates who are their friends versus strangers (in other words, their strong rather than weak ties).

\section{Hypotheses}

Because applicant qualification is a central consideration for employers when hiring, our study is designed to test the limits of preferences to refer well-qualified candidates in the face of competing motivations and incentives. Whereas past research has examined the effect of unemployment stigma on whether close ties were more likely than acquaintances to refer stigmatized candidates to an employer (Bond and Fernandez 2018), here, we are interested in whether referral behavior toward less-qualified candidates may be manipulated so as to mirror the referral likelihood for well-qualified candidates by means of large referral bonus incentives. Although referrers are more likely to refer well-qualified job candidates than lessqualified candidates, they may still be likely to refer less-qualified candidates if the motivation for seeking the referral bonus is strong enough. Specifically, we study the change in the likelihood that potential referrers refer a given candidate, who is either well-qualified and a good fit for the organization or less-qualified and less likely to be a good fit for the organization, in the face of increasing monetary incentives for referring to evaluate the impact on the overall candidate pool quality composition. Moreover, it is unlikely that incentivizing employees with referral bonuses will make them less likely to refer any given potential candidate, well qualified or less qualified. However, it is reasonable to expect that increasing a bonus incentive is more likely to increase the likelihood that an employee will refer a less-qualified candidate because there would be a clear motivation to make any referral instead of weighing only reputation or social appropriateness risks generally. In considering a well-qualified candidate, on the other hand, there is a lower risk of referring, and therefore it is reasonable to assume that there is a higher baseline in referral likelihood for such candidates. As such, the likelihood of referring well-qualified candidates may be less sensitive to positive incentives for referring. For these reasons, we hypothesize the following:

Hypothesis 1: The difference in likelihood between referring wellqualified job candidates and less-qualified candidates diminishes as referral bonuses increase.

In light of the factors reviewed above, we also ask whether there is a relationship between the size of the referral bonus and the difference in propensity to refer strong versus weak ties. Both Kim and Fernandez (2017) and Bond and Fernandez (2018) found a stronger tendency for referrers to refer friends than to refer strangers. 
However, the incentive effect of a referral bonus may interact with the influence of relationship strength between the referrer and referral candidate in ways that will alter this pattern. Specifically, we predict that as the amount of the referral bonus increases, the preference for referring close ties (friends) relative to weak ties (strangers) should diminish (cf. Beaman and Magruder 2012). ${ }^{3}$ Although there may be reasons why a high enough referral bonus incentive could even reverse the preference for friends (as in the adage "money and friends don't mix"), we conservatively subsume such a prediction and simply hypothesize the following:

Hypothesis 2: The difference in likelihood between referring friends and strangers diminishes as referral bonuses increase.

Finally, we study how such a convergence in the likelihood of referring welland less-qualified candidates is mediated by the strength of the social tie between the referrer and referral candidate. In other words, we are interested in how the two preceding mediators (qualification and strength of social tie) interact under increasing referral bonus stakes. As we expect candidate qualifications and the strength of the tie to be significant predictors of referral behavior, we should also expect that referring a candidate who is not well-qualified and not a friend is the most sensitive to the monetary bonus incentives.

First, when a candidate is not well qualified, there is no social tie, and there is no monetary incentive, there is no reason to make a referral in the first place. In this case, when a referral bonus is offered, it becomes the only positive motivation to refer. Thus, we expect a monetary bonus to cause the most significant increase in the referral likelihood for less-qualified strangers compared to the other three conditions, in which a potential referrer might have some other incentives to refer. Second, although we expect employee referrers to be less likely to refer strangers in general, we also think there is a possibility that strangers may be judged as likely less qualified than friends (net of whether or not this is objectively the case; Becker 1976). Several cognitive biases would predict that potential referrers are more likely to consider strangers to be less qualified than friends. In particular, in-group bias in conjunction with out-group homogeneity bias would lead to an expected increase in the likelihood that referrers would estimate friends to be higher quality relative to strangers when evaluating the same candidate (Yamagishi and Mifune 2009). For instance, even when comparing the exact same candidate with the exact same information available regarding the candidate's quality, friends may still automatically assume a higher baseline of quality from simply the positive association of their friendship. This tendency would also suggest that when there are concerns about a candidate's qualifications, the incentive effects of referral bonuses will be stronger for strangers.

Hypothesis 3: As referral bonuses increase, the referral likelihood for less-qualified strangers will increase faster than the referral likelihood for less-qualified friends and well-qualified candidates.

In conjunction, our three main predictions imply that monetary incentives in the form of referral bonuses have the power to materially alter the type of job candidates referred through employee referral programs. In the study design described below, 
we measure how much such referral decisions may change as determined by the level of monetary bonuses, the strength of the relationship tie between the employee referrer and the referral candidate, and the referral candidate's level of qualification.

\section{Data and Methods}

Using a survey vignette experiment with between-subject random assignment to conditions in an online labor market (Amazon.com's Mechanical Turk, henceforth "MTurk"), we study the effects of various amounts of referral bonuses paid to employee referrers who refer candidates who are then successfully hired and retained over a given probationary period. Vignettes present a hypothetical situation for respondents to consider theoretically relevant factors that can be systematically varied in the form of short descriptions (Rossi and Anderson 1982). This method allows us to exogenously determine variations in the key conditions of a potential referral's relevant qualifications for the job position and the strength of the referrer's social tie to the potential referrer as well as the referral bonus amount offered. The causal inferences regarding the effects of the hypothetical conditions of qualifications and strength of the social tie given referral bonus amounts on the outcome of referral likelihood are generated by this exogenous variation. Although critics argue that the vignette method is deficient in external validity, evidence using behavioral benchmarks demonstrates remarkable predictive power of real-world behavior (Hainmueller et al. 2015). To strengthen the external validity of our design, we validate that the survey sample has representative experience in making job referrals in the employment settings we test (discussed further below; Hainmueller et al. 2015).

\section{Study Population}

Subjects are recruited through Amazon MTurk to complete the survey online using Qualtrics. We use random assignment procedures to assign respondents to each experimental condition (see below). In contrast to academic lab studies, the demographic composition of the MTurk worker population is likely to have more experience in the traditional labor market and have similar income distributions to the U.S. population (Berinsky, Huber, and Lenz 2012; Buhrmester, Kwang, and Gosling 2011; Paolacci and Chandler 2014; Paolacci, Chandler, and Ipeirotis 2010). In order to mitigate concerns about the internal validity of the data, we limit the availability of our online vignette survey (in the form of an MTurk Human Intelligence Task [HITS]) to workers in the United States with a more than 95 percent approval rating for prior HITS completed. We also insert attention and manipulation checks into the study in order to limit concerns about the extent to which respondents are following the protocol. Overall, 1,473 participants were recruited and paid $\$ 0.75$ for participating in a study described as a "less than 7 minute survey on job market behavior."

Respondents are relatively experienced, with an average of 14 years of prior work experience. ${ }^{4}$ The mean age is 35 years, and 46 percent are female. ${ }^{5}$ The experimentally identified main effects measured in this study do not significantly vary 
with any demographic characteristic; therefore, we do not discuss these respondent demographic characteristics further. Referring is a dominant mode for job matching in the U.S. labor market (Smith, Marsden, and Hout 2014; see also Rubineau 2015), and the experience of our respondents is no exception. Overall, almost half of our respondents ( 49 percent) have direct experience with referral behavior in the labor market, with 33 percent having themselves been referred to a job opportunity to which they then applied and 27 percent having referred someone else (including about 16 percent having done both). ${ }^{6}$ This frequency of referral experience, in conjunction with the overall labor force and industry participation (discussed below), makes this a convenient source of experimental subjects and a well-qualified set to test the effects of candidate qualifications and referral bonuses on referral behavior.

We use the information technology (IT) industry as the setting for our hypothetical vignettes, as many of the MTurk users who participated in our study have IT employment experience. More than 16 percent of respondents report being currently employed in an IT position, not including those reporting current unemployment or MTurk as employment. Indeed, the IT industry is the most frequently cited industry, ahead of sales (13 percent) and education (10 percent), among 18 broad industry classifications self-reported by our MTurk respondents. Importantly, the general findings are replicated when restricting the pool of respondents to the subsample of the 212 MTurk users reporting IT industry employment experience (which we refer to as the "IT subsample" below).

\section{Experimental Survey Vignette Design}

We test whether it is indeed the case that using bonuses to incentivize referrals may deliver more low-quality candidates relative to qualified ones as compared to a counterfactual nonbonus setting. We examine the difference between two candidate qualification conditions to study the differential influence of greater referral bonuses on the quality of the candidates referred to the organization. We also randomly vary the strength of the social relationship (friend versus stranger) between the potential referrer and candidate. Finally, we collect open-ended responses from our participants concerning what they felt were the most important considerations in making their referral decisions. This qualitative evidence will be used to inform theoretical conclusions we draw from the empirical findings based on the main referral experiment.

The fact that we randomly assign subjects to the conditions means that all omitted factors that might be associated with the responses to any two referral variables are controlled for within the limits of sampling error. We include two manipulation questions to validate that respondents are sensitive to the various conditions they are randomized to, and we also include an attention check to ensure that respondents understand the key condition of the current employment status of the candidate under consideration.

Before entering the main study, all participants read a cover page stating, "On the next 2 pages you will find a short description of a hypothetical situation. Please read the description carefully and answer how you would behave in those situations. 
At the end of the survey, there will be a few short questions about your own employment experience."

Respondents then completed a survey we developed to learn about how these subjects say they would behave in hypothetical scenarios involving the use of referrals. All hypothetical situations concern a potential job candidate named Ben. A description of the hypothetical situation follows. All respondents are told to do the following: "Please imagine: You have been working for an IT company as a Software Engineer for 5 years. You like your job. Your responsibilities include development and performance analysis of several software products. Recently, the Human Resources (HR) department at your firm has been sending emails encouraging employees to refer Software Engineers."

At this stage, respondents are randomly assigned to conditions that vary in the level of monetary bonus awarded in the company, the quality of the candidate they will consider, and the strength of the social tie (friend versus stranger) they have to the candidate. We vary the level of monetary incentives by constructing six different price points for the referral bonus: no bonus ( $\$ 0), \$ 100, \$ 250, \$ 1,000, \$ 5,000$, and $\$ 10,000$. The nonlinear progression of the price points chosen is by design. In a previous study, Kim and Fernandez (2017) found that including a single referral bonus amount $(\$ 1,000)$ was insufficient to make claims that the monetary incentive was high enough to induce a switch from strength-of-tie considerations dominating the decision of whether or not to refer candidates to a job opening. ${ }^{7}$ By choosing bonus amounts that increase at an increasing rate, our study is able to estimate potential nonlinearity in the influence of monetary motivation on the likelihood to refer weak ties as well as the quality of the candidate referred. Also, extending the range of referral bonuses to $\$ 10,000$ is based on empirical observations from the field, especially in the IT sector ${ }^{8}$ and from reports in popular press. ${ }^{9}$

Next, because we are interested in measuring the trade-offs between a referrer's consideration of a candidate's qualifications for the job opportunity and the monetary bonus they would be rewarded if their referral is hired, we created two qualification conditions: well qualified and less qualified for the job at the company. The operationalization of these qualification conditions is constrained by the plausibility of our vignette design, using hypothetical social media recommendations on a professional networking site. We mitigate this limitation through complementary quality signals described further in our experimental design section. ${ }^{10}$

Finally, following other designs manipulating the strength of tie experimentally (Kim and Fernandez 2017; Bond and Fernandez 2018), we conceptualize strong ties as "friends" and weak ties as "someone you do not know well." We also operationalize the professional relationship as one in which the employee referrer is likely to be in at least as senior a position, if not a more senior position, than the potential job candidate under consideration so as to control for other considerations regarding how the referrer may think their offer would be otherwise construed (Marin 2012). Based on similar logic, respondents are also told that they like their job so as to control for any possible perverse incentives motivating the referral behavior.

As listed in Table 1, in our survey design, we interact the six levels of referral bonus amount (no bonus [ $\$ 0], \$ 100, \$ 250, \$ 1,000, \$ 5,000$, and $\$ 10,000$ ) with the two 
Table 1: The 24 varying conditions comprising the experimental vignette study.

\begin{tabular}{l}
\hline Referral Bonus Amount (six conditions): \\
\hline No bonus ( $\$ 0)$ \\
$\$ 100$ \\
$\$ 250$ \\
$\$ 1,000$ \\
$\$ 5,000$ \\
$\$ 10,000$ \\
Candidate Quality (two conditions): \\
\hline Well-Qualified \\
Less-Qualified \\
Strength of Social Tie (two conditions): \\
Friend \\
Stranger
\end{tabular}

candidate quality conditions and the two strength-of-social-tie conditions. This generates a total of 24 total conditions. The breadth of conditions allows us to study the effects of increasing referral bonus incentives on our two dimensions of interest: the strength of the social tie and the quality of the job candidate being referred.

For all subjects randomly assigned to any referral bonus condition (i.e., excluding only subjects assigned to the no bonus [\$0] condition), the following information is placed on the same page below the previous description of the hypothetical situation they are called on to consider: "If a referral successfully gets through the interview process, gets hired, and stays with the company for at least 3 months, the person who referred this new employee receives a monetary bonus of $[\$ 100, \$ 250$, $\$ 1,000, \$ 5,000, \$ 10,000] . "$ Respondents in the no bonus (\$0) condition do not see any additional information at this stage.

A description of the potential referral's current employment and job qualifications then follow. First, all subjects are randomized into either a friend or stranger relationship status condition with the potential referral. For the friend condition, subjects are told the following: "Now, please consider: There is a potential job candidate, Ben. Ben is a close friend of yours..." For the stranger condition, subjects are told the following: "You have talked to Ben before, but you do not know him well."

Following the description of the job candidate's social relationship to the employee referrer, subjects are given several signals reflecting how well qualified and fit Ben is for the job at the subject's hypothetical employer. In particular, subjects in the well-qualified condition read that, "Based on a quick glance at Ben's professional networking social media page, it seems that Ben would be a great fit to your company." For the stranger condition, subjects read that, "It seems that Ben might not be a good fit for your company." All subjects read the following: "Ben has been working for 3 years as a Junior Software Developer at Boonstock, a U.S. 
software development company. Below are some of Ben's recommendations from professional social networks."

Following this information, we provide two sets of two public endorsements for Ben from hypothetical coworkers from a hypothetical place of current employment: one from the chief technology officer at Boonstock and one from a fellow software engineer at Boonstock, which we vary across the two quality conditions (provided in the online supplement). ${ }^{11}$ To reflect the fact that such public endorsements would unlikely include explicitly negative language, the less-qualified condition uses more vague and hedging language in place of exclamatory praise about specific deliverables, as provided in the well-qualified condition.

\section{Dependent Variables}

We conceptualize the motivation that employees have to refer candidates to their employers on the basis of their employee-employer relationship as one concerning the employee's reputation. In this article, we study explicitly expressed quality rather than elements that may imply or convey a representation of underlying quality. Therefore, we first control the conditions relating to the employee strength of relationship with the employer by setting all hypothetical relationships to those that have lasted five years of working for the employer. Additionally, respondents are also told that they like their job so as to control for any differences in how much they care about their employment attachment and whether the opportunity is one that would be attractive to a prospective referral.

Below, we describe the hypothetical vignette. Participants are asked about two key outcome variables in which we ask them to play the role of potential referrers. Specifically, subjects are reminded that, "The IT company you are working for has asked employees to refer Software Engineers. [HR offers a monetary bonus of $\$ 100$ / $\$ 250 / \$ 1,000 / \$ 5,000 / \$ 10,000$ if a referral successfully gets through the interview process, gets hired, and stays with the company for at least 3 months. ${ }^{12}$ On a scale from 0 to 100 percent, where 0 is never and 100 is certainly, how likely are you to do the following: (1) contact Ben and encourage him to apply for the job as your referral, and (2) contact Ben and encourage him to apply for the job without mentioning your name (in this case, you will not be eligible to receive the referral bonus)."13

Respondents are given the opportunity to answer these two questions either using a slider scale from 0 to 100 or in a text box that updates automatically if respondents use the slider (with vice-versa automatic updating). The ordering of these two response questions is counterbalanced to eliminate order effects from the responses. The former item ("Refer with Name") measures the likelihood of referring when the referrer associates their name with the candidate. This is the key dependent variable of interest in this study.

The latter item ("Refer Without Name") captures the likelihood of referring the candidate when the person can protect their reputation. The difference between the second and first measures (Refer Without Name and Refer With Name) gives a measure of referrer distancing from the candidate in referring. The difference will be

larger to the degree that the referrer is protecting their reputation by avoiding being 
associated with a candidate. Therefore, we use this measure as an assurance check that the main manipulation of increasing monetary bonuses overshadows a referrer's latent sphere of reputation concern through monetary incentives. Although such reputation protection is unlikely in the presence of referral bonuses generally, subjects may exhibit reluctance in referring unqualified candidates and those they do not know well if they worry that the referral's work would reflect poorly on them, especially when there is no referral bonus on the line. Such reluctance is captured by the distancing measure.

We also ask a follow-up question on a separate page, "Put another way, would you refer Ben?" with only two options, "yes" or "no" available as possible answer choices. Although the main dependent variable described above captures the uncertainty that potential referrers face in considering whether or not to refer, this follow-up question validates the direct employer implications concerning the actual candidates referred to hiring managers through the referral program.

Because we expect a possible interactive effect between the strength of the social tie and the importance of candidate quality in the consideration of whether or not to refer, we also include a measure of how qualified respondents perceive the candidate to be. Specifically, all respondents use a seven-point Likert scale to report, "How qualified do you think Ben is for the job?" These data allow us to test whether friendship increases the perception of candidate qualifications and whether this difference in perception (relative to strangers) mediates the likelihood to refer. Finally, we include two manipulation checks to ensure that subjects responded to the strength-of-tie condition and quality manipulation ${ }^{14}$ as well as an attention check. ${ }^{15}$

\section{Results}

With an important outcome of interest in this study being the quality of the pool of candidates who are referred to a job opening, we begin by first assessing directly whether the difference in probability of referring well-qualified job candidates versus less-qualified candidates diminishes as referral bonus amounts increase. As Figure 1 depicts, respondents become more likely to refer less-qualified candidates as the referral bonus amount increases. ${ }^{16}$ In support of hypothesis 1 , the difference in referral likelihood between well-qualified candidates and less-qualified candidates decreases from 36.6 scale points in the no bonus condition $(t=11.42)$ to 15.0 scale points in the $\$ 10,000$ bonus condition $(t=5.74) .{ }^{17}$ Restricting our sample only to respondents reporting the IT industry as their field of experience, the difference between the no bonus ( 29.97 scale points; $t=3.22$ ) and the $\$ 10,000$ bonus condition (14.35 scale points; $t=1.43$ ) is also reduced by more than half (see Figure A6 in the online supplement).

The most striking difference in the likelihood of referring less-qualified candidates is the difference between the no bonus condition and the next-lowest bonus condition of $\$ 100$. This difference between no bonus likelihood (mean likelihood: 46.3 percent) and the $\$ 100$ condition (mean likelihood: 59.7 percent) is a statistically significant 13.4 scale points $(t=3.59)$. As the referral bonus offered increases, the likelihood of referring the less-qualified candidate continues to increase only 


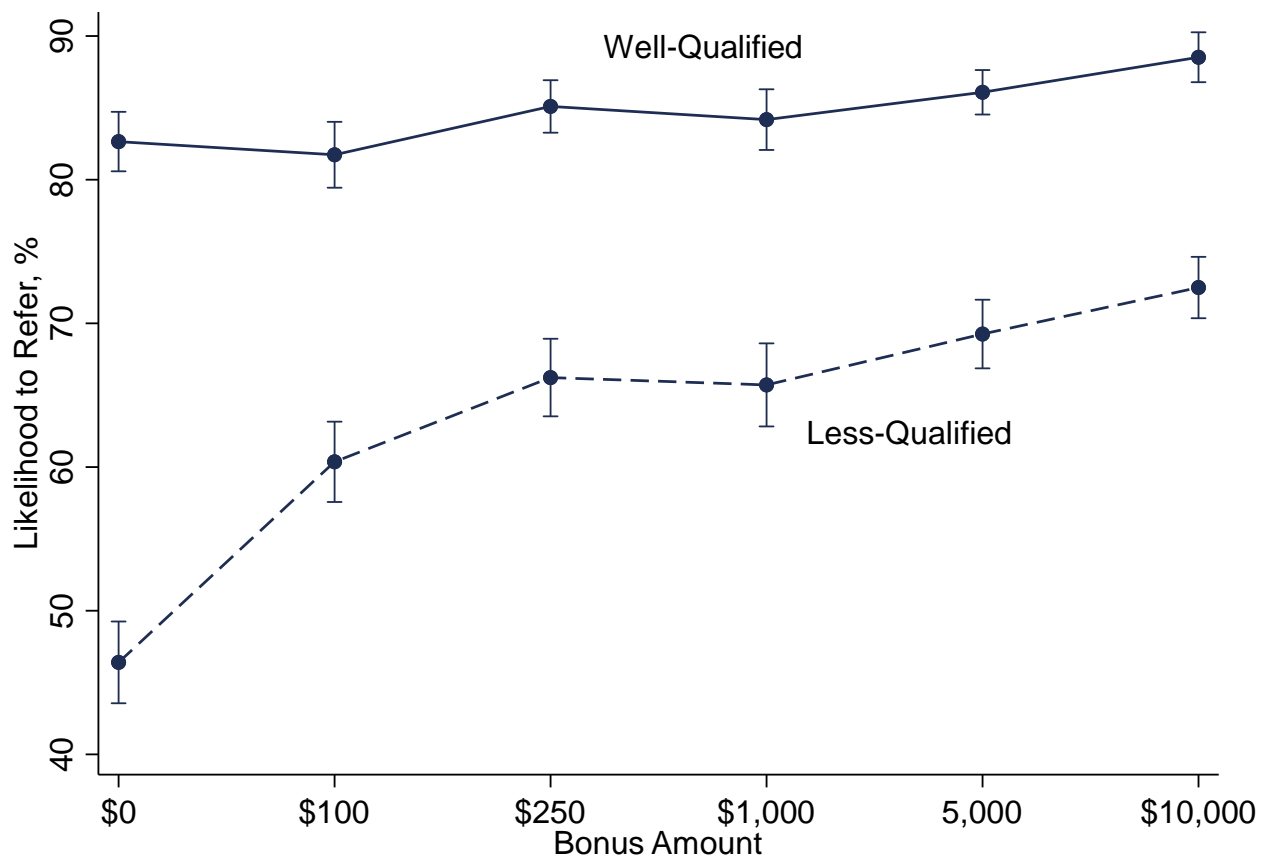

Figure 1: Less-qualified candidates referred more given (higher) bonuses (\% likelihood).

marginally. Also notable is that the likelihood of referring a well-qualified candidate appears to be insensitive to the bonus conditions; there are no statistically significant differences between any two bonus conditions for well-qualified candidates.

In addition, the difference in referral patterns between well-qualified and lessqualified candidates is all the more stark when respondents are asked directly whether or not they would actually refer Ben ("yes" or "no" rather than the likelihood they would do so; see Figure A1 in the online supplement). In fact, nearly 100 percent of respondents considering a well-qualified candidate reported that they would refer Ben across any bonus or no bonus conditions. Although never reaching nearly as uniform a likelihood of referring as when considering a well-qualified candidate, it is clear that a monetary bonus incentivizes referrers who are considering a less-qualified candidate to behave more like those considering a well-qualified candidate. Robustness checks demonstrate that referrers are more likely to protect their reputation by distancing themselves more from unqualified candidates, supporting the overall conclusion that candidate qualification considerations dominate the referral decision despite the moderating effect of bonus incentives (see Figures A3, A4, and A5 in the online supplement).

We turn next to consider hypothesis 2 , the difference that the strength of tie makes in a referrer's decision to refer, irrespective of the candidate's qualification for the job opportunity (see Figure 2). The evidence regarding the effect of the referral bonus amount on the difference in likelihood to refer when considering friends versus strangers is clearly in support of hypothesis 2 . Once there is any money offered in the form of a referral bonus by an employer, referrers are just as likely to refer a potential candidate who is a stranger as one who is a friend. 


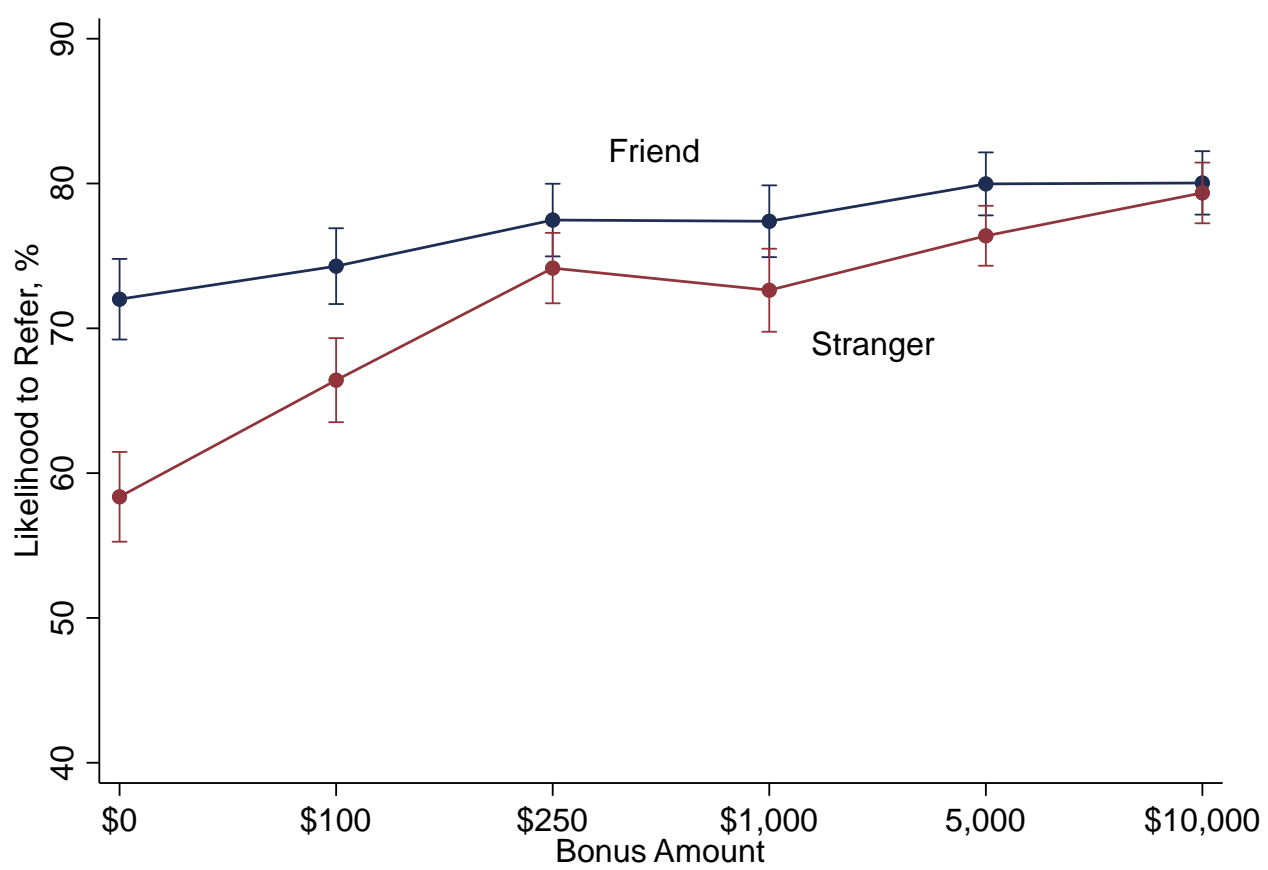

Figure 2: Referral patterns for strangers approach that of friends given (higher) bonuses.

The only condition in which referrers are distinctly less likely to refer a potential candidate whom they do not know well is in the no bonus condition, in which strangers are 12.1 scale points less likely to be referred than friends $(t=3.11)$. This same is true for the IT subsample of respondents; only in the no bonus condition are friends more likely to be referred than strangers with any statistical significance (the difference is 20.9 scale points; $t=1.97)$. Viewing this analysis in terms of the "price" at which referrals are treated like friends, the gap between strangers and friends is virtually eliminated with a bonus of $\$ 100$ but is gone when the bonus reaches $\$ 250 .^{18}$ This pattern is also robust to supplemental analyses on the propensity of referrers to distance themselves from less-qualified candidates no matter the strength of the social tie between the referrer and the candidate (see the Distancing Measure section in the online supplement).

Finally, we consider the evidence pertaining to hypothesis 3 . We examine the influence of the above two explanatory variables for differential referral likelihoods (candidate quality and strength of tie) in conjunction with one another to distinguish which consideration dominates under the influence of referral bonuses in the decision to refer. From Figure 3, it is easy to see that quality considerations dominate the decision to refer. The results continue to hold if the alternative dependent variable is used when measuring whether the referrer would actually execute the referral decision (yes or no; see Figure A2 in the online supplement) as well as if we restrict the analysis to only the IT subsample of respondents. ${ }^{19}$

This finding is consistent with hypothesis 3 in that as the referral bonus amount increases, the referral likelihood for less-qualified strangers will increase faster than the referral likelihood for less-qualified friends or well-qualified candidates. 


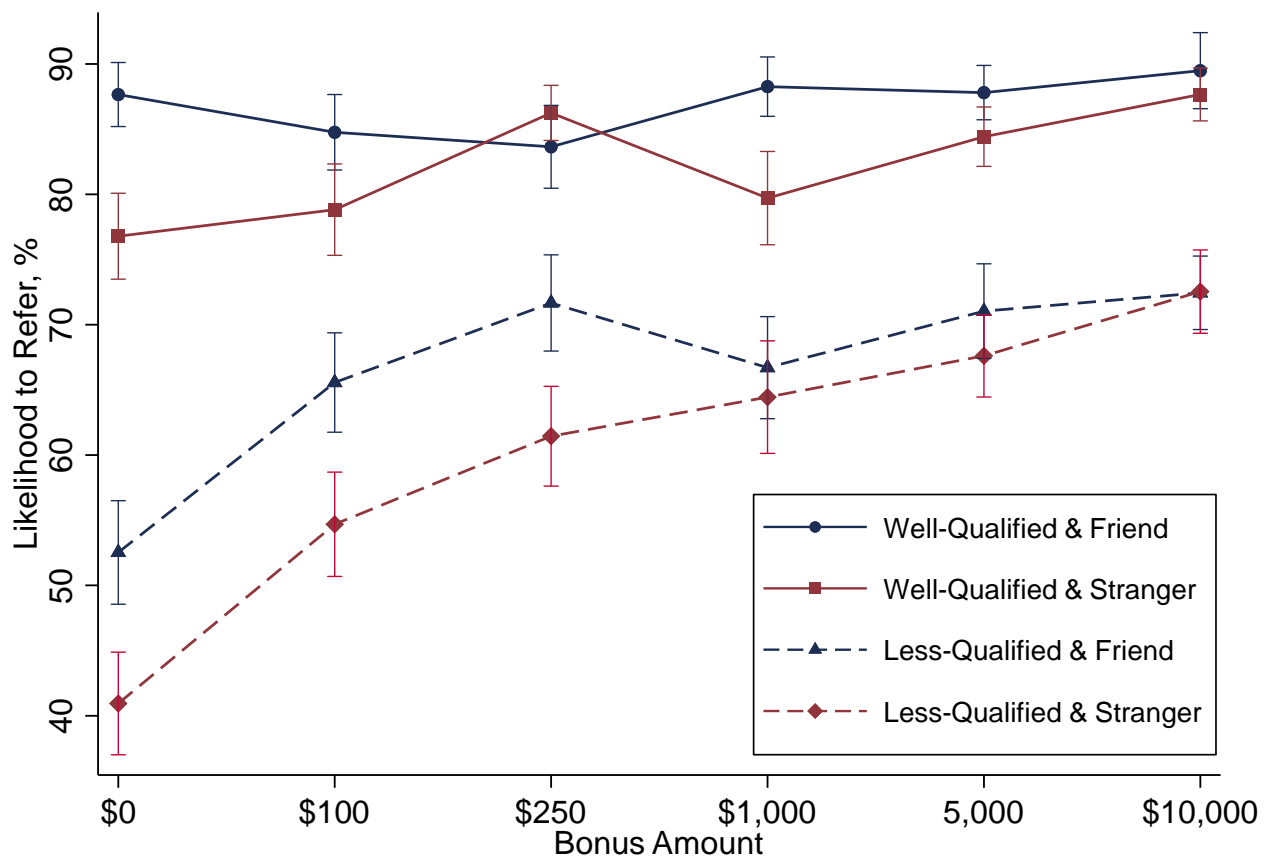

Figure 3: Candidate quality dominates strength-of-tie considerations in referral likelihood.

Moreover, additional mediation analysis suggests that this result is not explained by friendship between the referrer and the candidate, influencing the perception of candidate quality. For the unqualified candidate condition, the likelihood of referring was not significantly mediated by this effect. ${ }^{20}$

We interpret these results as emphasizing the direct effects that referral bonuses have on referrers' likelihood of referring any candidate, well-qualified or lessqualified, friend or stranger. Although bonuses increase the propensity to refer less-qualified candidates, they have the largest positive effect on incentivizing referrals for less-qualified strangers (hypothesis 3). By putting money on the table, employers increase the propensity to make any type of referral in general. Because referrers are already very likely to referrer well-qualified candidates, especially if they know them well, the direct effect of adding referral bonuses to the referral considerations makes the biggest net difference in the likelihood that less-qualified candidates and strangers are referred.

\section{Summary and Conclusion}

Past research on the decision to refer has been limited in its ability to address the motivations that lead potential referrers to facilitate job matches (e.g., Fernandez and Castilla 2001). Qualitative researchers Smith (2005) and Marin (2012) have offered important insights about these motivations and processes. Essentially, when deciding whether to refer someone, referrers are placing themselves in a position of potential role conflict, needing to balance their motivations for helping connections find job opportunities with concerns regarding their reputation with the employer 
and the potential referral. From the employer's perspective, how this tension is resolved has important consequences. To the extent that monetary incentives shift an employee's considerations away from finding the best matches for the employer, referral bonuses may be counterproductive by increasing the chances that lower-quality candidates are referred. As in numerous spheres of life in which market and nonmarket logics collide (e.g., Titmuss 1970; Healy 2006; Zelizer 2017), commodifying social relations can produce harmful, unintended consequences.

In this study, we seek to connect the extant research on referrers' motivations to the business reality that many organizations use employee referral programs to incentivize employees to refer potential applicants from their social networks. We use a survey vignette experiment in order to surface the mental models people use when balancing different considerations as they contemplate making referrals. We find that referrers are more likely to refer less-qualified candidates when there is a referral bonus offered, whether this is measured by the likelihood of referring or by the percent of respondents reporting that they would make an affirmative referral decision. Although referrers consistently exhibit high levels of referring likelihood for well-qualified candidates, the likelihood that a referrer will refer a less-qualified candidate increases with the amount of the referral bonus offered.

Importantly, the qualification level of the candidate relative to the job opening is the dominant factor in whether or not they receive an employee referral to the opening. Although whether or not the candidate under consideration is a friend matters when there is no bonus incentive to referring, once there is money on the table, referrers tend to refer candidates they do not know well with a likelihood similar to that of referrals who are considered friends. This pattern is also robust to supplemental analyses on the propensity of referrers to protect their reputation by distancing themselves from less-qualified candidates, no matter the strength of the social tie between the referrer and the candidate.

Within the limits of our vignette design, these results support the idea that financial incentives can alter the weights given to the quality of the potential job candidate and the importance of the strength of the relationship tie between the referrer and the job candidate. The fact that referral bonuses do indeed influence the propensity of referrers to refer less-qualified candidates demonstrates the tradeoffs that brokers face in connecting candidates to jobs. Prior research shows that when controlling for the opportunity to refer and the quality of the candidate, referrers are more likely to refer friends even when there is a potential cost to doing so either in a foregone bonus (Kim and Fernandez 2017) or reputation costs (Bond and Fernandez 2018). However, when the opportunity to refer is open to any potential candidate in one's social network, it stands to reason that referrers are more likely to refer professional acquaintances rather than close ties if they think it will increase their chances for a contingent bonus (Beaman and Magruder 2012). Findings from our study add a richer understanding of how the tradeoffs facing an employment broker (in this case, an employee referrer) are susceptible to personal financial gain amidst reputations with their employers and their concerns for the welfare of their network ties.

These results also have implications for the larger debate about incentives producing unintended negative outcomes due to crowding out. Although past 
research views these issues as a tug of war between extrinsic and intrinsic motives (Benabou and Tirole 2003; Deci et al. 1999; Frey 1994; Frey and Oberholzer-Gee 1997; Gneezy and Rustichini 2000), our results point to an additional dimension being traded off as referral decisions are made. In the studies cited above, the extrinsicintrinsic tradeoffs are assessed only from the perspective of the actor introducing the extrinsic reward. In the present case, as in many others in which brokers stand between pairs of actors with conflicting interests (see, e.g., Fernandez and Gould 1994), the issue also arises as to which party the broker identifies as having intrinsic worth (Heimer 1992). Here, our subjects are clearly privileging strong ties even as they consider the enticement of a referral bonus.

Finally, these findings have important implications for organizational practice. Many organizations use employee referral programs to recruit new employees, thus affecting organizations' pipelines of potential candidates. The current dominant view is that referral practices are a cost-effective way to access qualified candidates. What this study demonstrates, however, is that there may be significant hidden and hitherto unappreciated costs to referral programs. To the degree that referral bonuses reduce concerns about the quality of the potential candidate among potential referrers, the hiring pipeline can become clogged with candidates with questionable job qualifications or productivity potential. In conclusion, we offer the following caution to human resources professionals: the use of even small recruitment bonuses can unintentionally and unwittingly reduce organizations' recruitment effectiveness.

\section{Notes}

1 According to Career Builder, the largest online career services website, 69 percent of employers say they have a formal employee referral program (Career Builder 2010). A 2006 survey conducted by the DirectEmployers Association reported that 88 percent of member employers rated employee referrals above all other sources for generating quality new hires. Recruiters consider referrals to be their best source of hires, according to Jobvite's Recruiter Nation Study (2017), which also reports that 35 percent of job seekers obtained their current or most recent position via referral. Referral programs are present in organizations ranging from federal agencies (e.g., The U.S. Office of Personnel Management [2018]) to Silicon Valley startups (Glover 2014).

2 "Strong tie versus weak tie" and "friend versus stranger" are used interchangeably in this article, as the former is common theoretical terminology but the latter is the translation used in the research design employed here.

3 In this respect, the Beaman and Magruder study is of particular interest. In a hybrid laboratory-field experiment study conducted in Kolkata, India, they found that when referrers are paid referral bonuses contingent on the performance of their recruits, employees responded by recruiting coworkers more often than relatives (2012:3575). However, they also found that it is only in the high-stakes condition (bonus contingent on referral's performance) that high-performing workers themselves successfully referred higher-performing recruits as opposed to workers who did not perform well (2012: 3590). Thus, their findings suggest that quality concerns are only activated in certain high-stakes settings. Moreover, even in the high-stakes condition (bonus contingent on recruit's performance), only employees who were able to properly gauge qualities that 
could translate into high performance (by being higher performing themselves) were able to translate the motivation into better performance for the employer.

4 Of the 1,473 participants, 1,353 answered all of the demographic questions.

5 Forty-seven percent have less than four years of college education, and 42 percent have 4 years of college education; 49 percent have less than $\$ 50,000$ combined annual household income.

6 These proportions are slightly lower than national figures. In the nationally representative General Social Surveys conducted by the National Opinion Research Center (1991), 60 percent of employees found their jobs via social contacts, although not necessarily via employee referrals, and 52 percent of employees referred a social contact to a job opportunity in the last 12 months (Smith et al. 2014).

7 Further, initial pilot studies for the present research conducted with executive master's in business administration (eMBA) students motivated the high end of the bonuses offered (indeed, some reported referral bonuses from the eMBAs' own career histories were well beyond the highest price we incorporate into this study). Note that although the quality of the candidate was not manipulated in pilot studies with the eMBA population, similar results were found concerning the strength-of-tie effect using the eMBA data.

8 In particular, in informal exploratory studies using eMBA students.

9 See Brown (2014).

10 We considered varying the length of the probationary period preceding the potential payment of the referral bonus with the thought of attenuating the importance of quality considerations. To the extent that if there were no probationary period, subjects might not demonstrate any qualification concerns as opposed to a condition of a long probationary period, during which the impact of poor referral quality has a greater chance of influencing the referrer's reputation with the employer. However, we simplified the design to keep this element of probationary period constant in our study for two main reasons. One reason is that although some organizations do not have a probationary period, most do; therefore, this setting speaks to the broadest set of real-world conditions (WorldatWork 2016). The second reason is that this study is not meant to test the probationary period effects. From a human resources standpoint, conclusions based on these data would stand even for organizations without probationary periods. If it is found that monetary incentives increase the likelihood that less-qualified candidates are referred in our setting, it is unlikely that they will care that this went untested in a nonprobationary period setting. Inferences about referral bonuses and the quality of a candidate would also stand when referrers face a greater risk to their reputations during a probationary period.

11 To be clear, all respondents see recommendations from both coworkers. However, the content of each recommendation is altered so as to reflect either a well-qualified or less-qualified candidate, as seen in the online supplement.

12 Bracketed information is not present in no bonus condition.

13 Subjects are also told in parentheses following the above question prompt that, "The following two questions are not mutually exclusive. We are interested in how likely you are to refer Ben in either case."

14 Specifically, our manipulation-check questions ask, "How well do you think you know Ben?" and "How qualified do you think Ben is for the position at your company?" Responses fall on scales from 1 to 7 , where 1 is "I do not know him at all" and "not at all qualified," respectively, and 7 represents "We are best friends" and "extremely 
qualified," respectively. Patterns for both manipulation checks follow expectation, and results remain robust to removing outliers.

15 Specifically, our attention-check question asks, "Which of the following is true about Ben according to the given setting?" Subjects can choose among the following: Ben is a "personal assistant," "junior software developer," "senior graphic designer," or "freelancer." These options are randomly ordered across surveys. Fifty-two respondents failed to give the correct response of "junior software developer." We do not remove these respondents because results are not sensitive to their exclusion.

16 For this figure, we pool respondents in the friend and stranger conditions within the randomized qualification conditions.

17 Results from analysis of variance tests confirm that the difference between the likelihood to refer well-qualified and less-qualified candidates in the no bonus condition is statistically different from the difference in any of the bonus conditions (F statistic $=25.01$ ). Moreover, except for the no bonus condition, the difference in referral likelihood stays the same for all the levels of referral bonus.

18 Using the alternative dependent variable (the percent of respondents responding "yes" to whether they would actually refer the candidate), we find that 82 percent of respondents would refer the candidate if they are a friend in the no bonus condition as compared to 65 percent for strangers (see Figure A1 in the online supplement). Although there are small differences in the statistical significance of the results (e.g., for the likelihood measure presented in Figure 2, the standard errors for strangers and friends do not overlap, whereas they do overlap in Figure A1 in the online supplement), the same general pattern across bonus conditions is obtained for both these measures of the dependent variable. These results come when pooling the quality conditions within the strength-of-tie category.

19 The only difference of substance between the two measures in both the full sample and the IT subsample occurs in the no bonus conditions. With this measure, a nearly equal percentage of respondents would refer well-qualified candidates no matter their strength of tie to the candidate as opposed to respondents in the less-qualified condition, in which significantly more respondents (22 percent in the full sample) in the friend condition would refer the less-qualified candidate than those in the stranger condition.

20 The quality perception enhancement for friends in the well-qualified condition, however, does mediate the likelihood of referring. Results are available upon request.

\section{References}

Başbuğ, Gökçe. 2017. “Essays on Job Search, Unemployment, and Regulatory Compliance." Doctoral dissertation, Sloan School of Management, Massachusetts Institute of Technology. Retrieved from https://dspace.mit.edu/bitstream/handle/1721.1/ 112038/1006384870-MIT . pdf? sequence=1.

Beaman, Lori, and Jeremy Magruder. 2012. "Who Gets the Job Referral? Evidence from a Social Networks Experiment." American Economic Review 102:3574-93. https://doi . org/10.1257/aer.102.7.3574.

Becker, Gary S. 1976. “Altruism, Egoism, and Genetic Fitness: Economics and Sociobiology." Journal of Economic Literature 14:817-26.

Benabou, Roland, and Jean Tirole. 2003. "Intrinsic and Extrinsic Motivation." The Review of Economic Studies 70:489-520. https://doi .org/10.1111/1467-937X. 00253. 
Berinsky, Adam J., Gregory A. Huber, and Gabriel S. Lenz. 2012. "Evaluating Online Labor Markets for Experimental Research: Amazon.com's Mechanical Turk." Political Analysis 20:351-68. https://doi .org/10.1093/pan/mpr057.

Bidwell, Matthew, and Isabel Fernandez-Mateo. 2008. "Three Is a Crowd? Understanding Triadic Employment Relationships." Pp. 142-78 in Employment Relationships: New Models of White Collar Work, edited by P. Capelli. Cambridge, UK: Cambridge University Press. https://doi.org/10.1017/CB09780511611544.006.

Bond, Brittany M., and Roberto M. Fernandez. 2018. “Networks or Lemons?” Unpublished manuscript.

Brown, Kristen V. 2014. “Startup Offers \$20,000 for New Recruits." SF Gate, June 18. Retrieved September 29, 2017. http://www.sfgate.com/technology/article/ Startup-offers-20-000-for-new-recruits-5560929.php.

Buhrmester, Michael, Tracy Kwang, and Samuel D. Gosling. 2011. “Amazon's Mechanical Turk: A New Source of Inexpensive, yet High-Quality, Data?" Perspectives on Psychological Science 6:3-5. https://doi .org/10.1177/1745691610393980.

Burt, Ronald S. 1992. Structural Holes: The Social Structure of Competition. Cambridge, MA: Harvard University Press.

Career Builder. 2010. "Referral Madness: How Employee Referral Programs Turn Good Employees Into Great Recruiters and Grow Your Bottom Line. Retrieved September 29, 2017. https://cdn2.hubspot.net/hub/77464/file-17173226-pdf/ docs/careerbuilder_referral_madness_ebook.pdf.

Castilla, Emilio J. 2005. "Social Networks and Employee Performance in a Call Center." American Journal of Sociology 110:1243-83. https://doi .org/10.1086/427319.

Deci, Edward L., Richard Koestner, and Richard M. Ryan. 1999. “A Meta-analytic Review of Experiments Examining the Effects of Extrinsic Rewards on Intrinsic Motivation." Psychological Bulletin 125:627. https://doi .org/10.1037/0033-2909.125.6.627.

DirectEmployers Association. 2006. "Internet is Now the Primary Hiring Source for Employers." Retrieved September 29, 2017. https ://directemployers . org/2006/02/09/ internet-is-now-the-primary-hiring-source-for-employers/.

Fernandez, Roberto M., and Emilio J. Castilla. 2001. “How Much Is That Network Worth? Social Capital in Employee Referral Networks." Pp. 85-104 in Social Capital: Theory and Research, edited by N. Lin, K. Cook, and R. Burt. Chicago, IL: Aldine de Gruyter.

Fernandez, Roberto M., Emilio J. Castilla, and Paul Moore. 2000. "Social Capital at Work: Networks and Employment at a Phone Center." American Journal of Sociology 105:1288-356. https://doi.org/10.1086/210432.

Fernandez, Roberto M., and Isabel Fernandez-Mateo. 2006. "Networks, Race, and Hiring." American Sociological Review 71:42-71. https://doi.org/10.1177/ 000312240607100103.

Fernandez, Roberto M., and Jason Greenberg. 2013. “Race, Network Hiring, and Statistical Discrimination." Pp. 81-102 in Networks, Work and Inequality, edited by S. McDonald. Bingley, UK: Emerald Group Publishing Limited. https ://doi .org/10.1108/ S0277-2833(2013)0000024007.

Fernandez, Roberto M., and M. Lourdes Sosa. 2005. “Gendering the Job: Networks and Recruitment at a Call Center." American Journal of Sociology 111:859-904. https://doi . org/10.1086/497257.

Fernandez, Roberto M., and Mabel Abraham. 2010. “From Metaphors to Mechanisms: Gender Sorting in(to) an Organizational Hierarchy." Research paper, Sloan School of 
Management, Massachusetts Institute of Technology. Retrieved from SSRN, 4779-10. https://ssrn. com/abstract=1589012.

Fernandez, Roberto M., and Mabel Abraham. 2011. “Glass Ceilings and Glass Doors? Internal and External Hiring in an Organizational Hierarchy." Research paper, Sloan School of Management, Massachusetts Institute of Technology. Retrieved from SSRN, 4895-11. https://doi.org/10.2139/ssrn.1804896.

Fernandez, Roberto M., and Marie Louise Mors. 2008. “Competing for Jobs: Labor Queues and Gender Sorting in the Hiring Process." Social Science Research 37:1061-80. https: //doi.org/10.1016/j.ssresearch.2007.10.003.

Fernandez, Roberto M., and Nancy Weinberg. 1997. "Sifting and Sorting: Personal Contacts and Hiring in a Retail Bank." American Sociological Review 62:883-902. https : //doi .org/ $10.2307 / 2657345$.

Fernandez, Roberto M., and Roger V. Gould. 1994. “A Dilemma of State Power: Brokerage and Influence in the National Health Policy Domain." American Journal of Sociology 99:1455-91. https://doi.org/10.1086/230451.

Fernandez, Roberto M., and Roman V. Galperin. 2014. "The Causal Status of Social Capital in Labor Markets." Pp. 445-62 in Contemporary Perspectives on Organizational Social Networks, edited by D. J. Brass et al. Bingley, UK: Emerald Group Publishing Limited. https://doi.org/10.1108/S0733-558X (2014)0000040022.

Fernandez, Roberto M., and Santiago Campero. 2017. "Gender Sorting and the Glass Ceiling in High-Tech Firms." Industrial and Labor Relations Review 70:73-104. https: //doi.org/10.1177/0019793916668875.

Frey, Bruno S. 1994. "How Intrinsic Motivation Is Crowded Out and In." Rationality and Society 6:334-52. https://doi .org/10.1177/1043463194006003004.

Frey, Bruno S., and Felix Oberholzer-Gee. 1997. “The Cost of Price Incentives: An Empirical Analysis of Motivation Crowding-out." The American Economic Review 87:746-55.

Glover, Holly. 2014. "How to Build Out a Recruiting Function in a Startup." LinkedIn Talent Blog, November 26. Retrieved March 19, 2018. https://business.linkedin.com/talent-solutions/blog/2014/11/ how-to-build-out-a-recruiting-function-in-a-startup.

Gneezy, Uri, and Aldo Rustichini. 2000. “Pay Enough or Don't Pay at All." The Quarterly Journal of Economics 115:791-810. https://doi .org/10.1162/003355300554917.

Gould, Roger V., and Roberto M. Fernandez. 1989. "Structures of Mediation: A Formal Approach to Brokerage in Transaction Networks." Sociological Methodology 19:89-126. https://doi.org/10.2307/270949.

Granovetter, Mark. 1974. "The Strength of Weak Ties." American Journal of Sociology 78:136080. https://doi.org/10.1086/225469.

Granovetter, Mark. 1983. "The Strength of Weak Ties: A Network Theory Revisited." Sociological Theory 1:201-33. https://doi .org/10.2307/202051.

Hainmueller, Jens, Dominik Hangartner, and Teppei Yamamoto. 2015. “Validating Vignette and Conjoint Survey Experiments against Real-World Behavior." Proceedings of the National Academy of Sciences 112:2395-400. https ://doi .org/10.1073/pnas . 1416587112.

Healy, Kieran. 2006. Last Best Gifts: Altruism and the Market for Human Blood and Organs. Chicago, IL: University of Chicago Press. https://doi.org/10.7208/chicago/ 9780226322384.001 .0001$. 
Heimer, Carol A. 1992. "Doing Your Job and Helping Your Friends: Universalistic Norms about Obligations to Particular Others in Networks." Pp. 143-64 in Networks and Organizations: Structure, Form, and Action, edited by N. Nohria and R. G. Eccles. Boston, MA: Harvard Business School Press.

Jobvite. 2017. "2017 Job Seeker Nation Survey: Finding the Fault Lines in the American Workforce." Jobvite. Retrieved September 29, 2017. https://www.jobvite.com/jobvite-news-and-reports/ 2017-job-seeker-nation-survey-finding-fault-lines-american-workforce/.

Katz, Daniel, and Robert L. Kahn. 1978. The Social Psychology of Organizations. 2nd ed. New York, NY: John Wiley \& Sons.

Kim, Minjae, and Roberto M. Fernandez. 2017. "Strength Matters: Tie Strength as a Causal Driver of Networks' Information Benefits." Social Science Research 65:268-81. https: //doi.org/10.1016/j.ssresearch.2016.11.003.

Manwaring, Tony. 1984. "The Extended Internal Labour Market." Cambridge Journal of Economics 8:161-87.

Marin, Alexandra. 2012. “Don't Mention It: Why People Don't Share Job Information, When They Do, and Why It Matters." Social Networks 34:181-92. https ://doi .org/10.1016/j . socnet.2011.11.002.

National Opinion Research Center. 1991. "General Social Survey.” Ann Arbor, MI: Interuniversity Consortium for Political and Social Research, 2016-06-30. https : //doi .org/ 10.3886/ICPSR35321.v3.

Obukhova, Elena. 2012. "Motivation vs. Relevance: Using Strong Ties to Find a Job in Urban China." Social Science Research 41:570-80. https://doi.org/10.1016/j.ssresearch. 2011.12.010.

Paolacci, Gabriele, and Jesse Chandler. 2014. "Inside the Turk: Understanding Mechanical Turk as a Participant Pool." Current Directions in Psychological Science 23:184-88. https : //doi.org/10.1177/0963721414531598.

Paolacci, Gabriele, Jesse Chandler, and Panagiotis G. Ipeirotis. 2010. “Running Experiments on Amazon Mechanical Turk." Judgment and Decision Making 5:411-19.

Petersen, Trond, Ishak Saporta, and Marc-David L. Seidel. 2000. “Offering a Job: Meritocracy and Social Networks." American Journal of Sociology 106:763-816. https ://doi .org/10. $1086 / 318961$.

Rossi, Peter H., and Andy B. Anderson. 1982. "The Factorial Survey Approach: An Introduction." Pp. 15-67 in Measuring Social Judgments: The Factorial Survey Approach, edited by P. Rossi and S. Nock. Beverly Hills, CA: Sage.

Rubineau, Brian. 2015. “Job Referrers: Who They Are and What They Do." Unpublished manuscript.

Rubineau, Brian, and Roberto M. Fernandez. 2015. "How Do Labor Market Networks Work?" Pp. 1-15 in Emerging Trends in the Social and Behavioral Sciences: An Interdisciplinary, Searchable, and Linkable Resource, edited by R. A. Scott et al. Hoboken, NJ: John Wiley \& Sons. https://doi.org/10.1002/9781118900772. etrds0168.

Saloner, Garth. 1985. “Old Boy Networks as Screening Mechanisms." Journal of Labor Economics 3:255-67. https://doi .org/10.1086/298055.

Smith, Sandra Susan. 2003. "Exploring the Efficacy of African-Americans' Job Referral Networks: A Study of the Obligations of Exchange around Job Information and Influence." Ethnic and Racial Studies 26:1029-45. https://doi.org/10.1080/ 0141987032000132478. 
Smith, Sandra Susan. 2005. "'Don't Put My Name on It': Social Capital Activation and JobFinding Assistance among the Black Urban Poor." American Journal of Sociology 111:1-57. https://doi.org/10.1086/428814.

Smith, Sandra Susan. 2007. Lone Pursuit: Distrust and Defensive Individualism among the Black Poor. New York, NY: Russell Sage Foundation.

Smith, Sandra Susan. 2008. "A Question of Access or Mobilization? Understanding Inefficacious Job Referral Networks among the Black Poor." Pp. 157-81 in Social Capital: An International Research Program, edited by N. Lin and B. H. Erickson. Oxford, UK: Oxford University Press. https://doi.org/10.1093/acprof : oso/9780199234387.003.0076.

Smith, Tom W., Peter V. Marsden, and Michael Hout. 2014. “General Social Survey: Cultural Module, 2012 Merged Data [United States] (ICPSR35478)." Ann Arbor, MI: Interuniversity Consortium for Political and Social Research. https://www.icpsr.umich. edu/icpsrweb/NADAC/studies/35478.

Titmuss, Richard Morris. 1970. The Gift Relationship: From Human Blood to Social Policy. London, UK: Allen \& Unwin.

U.S. Office of Personnel Management. "Performance Management." 2018. U.S. Office of Personnel Management. Retrieved March 19, 2018. https://www.opm.gov/policy-data-oversight/performance-management/ performance-management-cycle/rewarding/using-referral-bonuses.

WorldatWork. 2016. "Bonus Programs and Practices." WorldatWork. https://www . worldatwork. org/docs/research-and-surveys/ survey-brief-survey-on-bonus-programs-and-practices-2016.pdf.

Yamagishi, Toshio, and Nobuhiro Mifune. 2009. "Social Exchange and Solidarity: InGroup Love or Out-Group Hate?" Evolution and Human Behavior 30:229-37. https: //doi.org/10.1016/j.evolhumbehav.2009.02.004.

Zelizer, Viviana A. Rotman. 2017. Morals and Markets: The Development of Life Insurance in the United States. New York, NY: Columbia University Press.

Acknowledgements: We thank our colleagues at the Massachusetts Institute of Technology Sloan School of Management and elsewhere for their feedback on earlier versions of this article. We have also benefitted from help, advice, and feedback from Matthew Amengual, Rhett Andrew Brymer, Santiago Campero, John Carroll, Emilio Castilla, Minjae Kim, Ezra Zuckerman Sivan, Heather Yang, and participants in the Economic Sociology Working Group at MIT Sloan and the Ninth Annual Meeting of the People and Organizations Conference at The Wharton School.

Brittany M. Bond: Sloan School of Management, Massachusetts Institute of Technology. E-mail: bbond@mit.edu.

Tatiana Labuzova: Sloan School of Management, Massachusetts Institute of Technology. E-mail: labuzova@mit.edu.

Roberto M. Fernandez: Sloan School of Management, Massachusetts Institute of Technology. E-mail: robertof@mit.edu. 